“. . . Somos a consciência que reflete o mundo e somos afetividade que ama e odeia este mundo, e com esta bagagem nos identificamos e somos identificados por aqueles que nos cercam" (Lane, 1995, p. 62). ${ }^{1}$

Diretório Acadêmico Sílvia Lane. Suas idéias e gestos continuam fecundando o solo sedento de nossa América Latina.

\section{Notas}

1. Lane, S. T. M. (1995). A mediação emocional na construção do psiquismo humano. In S. T. M. Lane \& B. Sawaia (Eds.), Novas veredas da Psicologia Social. São Paulo, SP: Brasiliense.
Apoliana Regina Groff é estudante da $9^{\text {a }}$ fase do Curso de Psicologia da Universidade Regional de Blumenau e Secretária de Formação do Centro de Defesa dos Direitos Humanos de Blumenau. Endereço para correspondência: Universidade Regional de Blumenau, Rua Antônia da Veiga, 140; Blumenau, SC, 89012-900. apoliana10@yahoo.com.br

Josiele Bené Lahorgue é psicóloga, formada pela Universidade Regional de Blumenau e Coordenadora Geral do Centro de Defesa dos Direitos Humanos de Blumenau.

psicojosi@terra.com.br

\title{
A GUERREIRA SÍLVIA LANE E SUAS LIÇÕES DE "PACIÊNCIA HISTÓRICA: UM DEPOIMENTO EMOCIONADO
}

\author{
Helerina Aparecida Novo \\ Faculdade Boa Viagem-IMIP, Recife, Brasil \\ Maria de Fátima Quintal de Freitas \\ Universidade Federal do Paraná, Curitiba, Brasil
}

Quando lembramos de Sílvia, sabemos que não foi embora. Porque não foi. Sílvia está entre nós, inspiradora de tantos e tantos de seus alunos, orientandos, amigos, todos órfãos da pessoa gigante que é Sílvia. Sentimos falta - todos nós - de outros bons encontros, dos ótimos papos, do sempre presente cigarrinho, da lucidez, da generosidade ímpar que sempre foi a marca indelével da sua forma de estar neste mundo. Porque Sílvia nunca se deixou levar pela fogueira de vaidades da academia ou de qualquer outra fogueira da onipotência, da arrogância, das mesquinharias que tanto nos apequenam. Talvez, por isso mesmo, nem sempre ganhou o devido reconhecimento da Academia. Sílvia era uma fogueira, ela própria, iluminadora de caminhos, na sua admirável simplicidade.

Decidimos falar de Sílvia pelo ângulo dos afetos. Ela certamente gostaria muito disso. Só podemos falar então, da perspectiva dos nossos próprios afetos e das afetações que percebemos no entorno de Sílvia. Entendemos que a compreensão da sua alma generosa só pode ser minimamente alcançada dessa forma. Em Sílvia Lane, razão e paixão estavam sempre irmanamente constituindo a vida e a luta diária.

. . . alguns aspectos que marcam Sílvia Lane: a inquietação com a qual percorre a Psicologia, sem medo, sem acomodação, sem receio do novo e sem receio de voltar ao velho; o sentido histórico que caracteriza sua vida. . . a capacidade de ser professora possibilitando aos outros (inicialmente alunos) assumirem também o lugar de sabedores; a permanência na luta, pois Sílvia sempre está em ação... coletiva; e, por fim, notem que Sílvia Lane não fala no singular, porque se entende sempre no coletivo, sempre trabalhando por projetos que são de muitos parceiros ${ }^{1}$.

Ouvimos de Sílvia, tantas vezes, quando estávamos desanimadas, descrentes frente aos desafios que a todo momento o viver cotidiano nos impunha, que precisávamos compreender melhor o movimento das coisas. Que era necessário ter "paciência histórica". O nosso sentimento de urgência defrontava-se com o otimismo e a crença inabalável de nossa mestra nas possibilidades concretas da transformação do que víamos como barreiras das condições concretas de realização de uma vida humana digna. Entretanto, Sílvia tinha a completa lucidez de que os processos históricos não se fazem unicamente por nosso apressado voluntarismo, nem por nossa ingênua crença em algumas certezas do melhor caminho. Nesse sentido, a sua militância acadêmica alicerçava-se na busca de um maior e melhor conhecimento das pessoas, dos grupos sociais inseridos no concreto, com seus múltiplos modos de vida. Afirmava constantemente a importância da pesquisa científica 
aliada ao compromisso social, mas não submetida a qualquer ditame ideológico, sob o qual qualquer conhecimento estaria a priori enviesado.

Vamos, então, falar um pouco dos caminhos da nossa mestra...

\section{A Militância Acadêmica de Sílvia Lane}

Era uma profunda conhecedora das teorias no campo das Ciências Humanas e Psicologia, sejam clássicas ou não, estabelecendo sempre debates amistosos, respeitosos, mas profundos, buscando continuamente novos suportes teóricos e elementos que permitissem compreender o processo de construção social da vida psicológica, assim como os reflexos produzidos no cotidiano, que deveriam, sim, passar a ser o foco dos estudos dos psicólogos (as).

Assim foi que, com ela, trazendo para os vários cursos que ministrou - seja no Programa de Pós-Graduação em Psicologia Social da Pontifícia Universidade Católica de São Paulo (PUC-SP), nos seminários nacionais e internacionais em que foi convidada em outras universidades, nos pequenos cursos durante os Congressos da Associação Brasileira de Psicologia Social, Conselho Federal (e Regionais) de Psicologia e de outras entidades - passamos a nos debruçar sobre as produções e análises de Vygotsky, Wallon, Leontiev, Luria, Marx e Engels, Florestan Fernandes, Paulo Freire; de Agnes Heller e Ferenc Feher para discutir as emoções e a estética; de Serge Moscovici e Denise Jodelet, esta com quem nutria uma profunda e parceira amizade intelectual e de vida, de Ignácio Martín-Baró, com quem criou um laço de amizade teórica e política pela realidade da 'nossa América Latina' (como costumava dizer), entre tantos outros teóricos, trazendo-os sempre para uma perspectiva da realidade sócio-histórica latino-americana e dentro de um enfoque histórico-dialético.

É com ela que se passa a admitir, claramente, o lugar e o significado da Subjetividade na Constituição Humana, buscando-se elementos da Consciência que permitam compreender o seu processo de construção.

É com ela que vamos tendo, também, a articulação entre Atividade-Consciência-Identidade, sendo tal articulação atravessada pelo que denominava de Mediação Emocional-Afetiva e pelos Processos da Linguagem, materializando-se nos diferentes Processos Grupais e nas diversas Relações de Poder.

É Sílvia Lane que, numa proposta arrojada e corajosa, nos anos 70 e 80, propõe a compreensão de parte dos fenômenos grupais através da construção que faz a partir do sociograma de Moreno e alguns elementos da Teoria de Campo de Lewin - com o uso, do que ela denomina, de Análise Gráfica das Formações Grupais. Posteriormente, isto é renovado e superado com a perspectiva histórico-dialética dos Grupos, que passam a ser entendidos e analisados na perspectiva dos Processos Grupais, enfocando os fenômenos da Consciência, da Identidade e da Atividade, num tripé dialeticamente articulado e atravessado pelas Emoções e pela Ideologia materializada na Linguagem. Nas aulas de Sílvia, aprendemos a analisar e discutir a realidade concreta tendo como referência um modelo proposto pela mestra, modelo este que, infelizmente, tem sido pouco creditado a ela. A Figura 1 apresenta o Modelo Paradigmático para as Relações e Processos Grupais cuja autoria e produção aproveitamos para reforçar. "Este era o 'esquema de aula" com que Sílvia Lane nos brindava em suas análises no mestrado e doutorado em Psicologia Social na PUC-SP, nos idos da década de 1980:

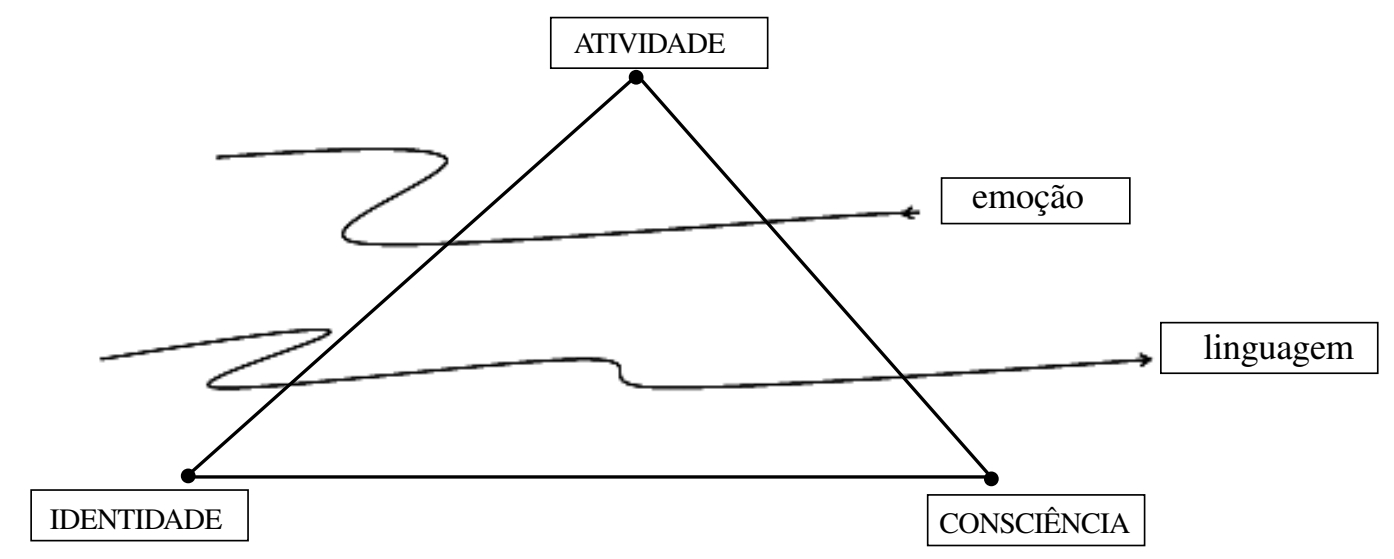

Figura 1. Modelo Paradigmático proposto por Sílvia Lane para a compreensão dos Processos Psicossociais e Relações Grupais: articulação dialética entre Atividade, Consciência e Identidade, atravessadas pela Emoção e Linguagem (anos de 1980 - Exposições e Produção de Sílvia Lane em suas aulas da Pòs-Graduação em Psicologia Social da PUC-SP). 


\section{O Caminho que se Fez ao Andar}

Desde os primórdios da institucionalização da Psicologia no Brasil e dos anos de formação, nos primeiros cursos que se iniciavam, em meados dos anos 60, em São Paulo, na PUC, vamos encontrar Sílvia Lane, juntamente com alguns leais e combativos colegas, enfileirando-se na busca de práticas e modelos teóricometodológicos para uma Psicologia comprometida com a realidade da maioria da população.

É com ela que começamos, nos idos dos anos $60 \mathrm{e}$ 70, a ouvir - e ter em suas aulas, palestras e trabalhos que realiza com alguns alunos, da Faculdade de Psicologia da PUC-SP - pela primeira vez, a defesa explícita de que a Psicologia deveria se estudar e se implicar com a realidade de nossa terra e nossa gente, brasileira e latino-americana, dentro da nossa perspectiva históricosocial de comprometimento com a justiça e a dignidade. Sílvia contava que, em meados dos anos de 1960, ia para os bairros da periferia da cidade de São Paulo, na Zona Leste fazer "algum trabalho da psicologia que, por excelência, já era um trabalho social e por isso mesmo deveria dizer a que se prestava" (sic). Anos mais tarde, e tendo sempre, em todos os momentos, a sua firme, mas doce e meiga, companhia como amiga-professora (que para nós era, também, como mestra-amiga), pudemos viver momentos ímpares compartilhando com Sílvia preocupações a respeito de nossa Psicologia e nossa Sociedade. Eram momentos compartilhados nas mais variadas situações, eram nas suas aulas na pósgraduação e nas palestras que ministrava pelo Brasil e América Latina, nos vários congressos e eventos em que tivemos o privilégio de tê-la como colega e companheira, e nos jantares ou happy-hours, após um longo dia de trabalho em que as discussões, análises e preocupações caminhavam na direção de unir esforços para a construção de uma Psicologia Brasileira que fosse, sempre, sensível e comprometida com o que acontecia com o povo de sua terra.

Alguns anos se passaram para que pudéssemos compreender que aquelas primeiras experiências que Sílvia Lane desenvolvia nos bairros da Zona Leste de São Paulo, tendo a seu lado, além dos seus alunos da Faculdade de Psicologia da PUC-SP, alguns outros colegas e também outros profissionais de outros campos, como medicina, enfermagem, educação, arquitetura, eram o gérmen do que veio a ser mais tarde conhecido como o Movimento de Saúde da Zona Leste da cidade de São Paulo. Além disto, estavam ali, em meados dos anos 60 , lançadas as bases - no campo da práxis - daquilo que seria mais tarde conhecida ou denominada como Psicologia Social Comunitária brasileira e latino-americana. Sílvia contava-nos com alegria e paixão - como sempre enfatizava, parafraseando Gramsci, de que 'tínhamos de ter paixão para poder chegar à transformação' - sobre as suas idas ao bairro, "no seu jipinho sem capota", com os alunos do curso, e que inúmeras vezes deparavam-se com todos os desafios inerentes ao 'o quê fazer?' Dizia ela: "Não sabíamos o quê fazer. Mas sabíamos que era uma outra Psicologia, e que esta outra Psicologia ainda estava por construir. Então, começamos a fazer este trabalho, com a única certeza de que era a hora da Psicologia estar ao lado do povo". Muitas vezes, Sílvia, nas aulas e em todas estas situações, nos dizia: "Agora é com vocês. Vocês é que têm de dar continuidade a este processo! A tarefa, agora, é de vocês! Vão adiante!" E seus olhos brilhavam, pois sabia que esta semente da paixão, da indignação diante da injustiça e do conformismo, assim como da necessária paciência histórica, ela estava, ali, dia a dia, pacientemente, plantando em cada um de nós!

É neste percurso efervescente em busca de uma Psicologia, autóctone e nacional, implicada com a realidade concreta, que vamos tendo o privilégio de acompanhar Sílvia Lane, procurando o caminho da construção de um conhecimento que fosse nossa e, por isto mesma, social. E esta busca dava-se ao lado dos "nossos irmãos latinos", como ela costumava chamar, que também estavam inquietos e insatisfeitos com a compreensão harmônica e a-histórica da sociedade latino-americana que, tradicionalmente, a Psicologia vinha fazendo através de seus modelos tradicionais.

\section{Enveredando pela América Latina}

Assim foi que em meados dos anos 70, duas professoras do Programa de Pós-Graduação em Psicologia Social da PUC-SP, Sílvia Lane e Maria do Carmo Guedes, empreendem uma viagem e histórica trajetória, passando por várias Capitais da América Latina, em busca destas parcerias e deste "compartir" teórico e político. Iniciava-se neste momento uma incipiente rede que vai se solidificando e criando laços e enraizamentos que perduram e crescem nas décadas seguintes, ampliando-se cada vez mais.

Iniciaram-se, aí, os caminhos para a construção de inúmeros debates, congressos, eventos, redes de psicólogos (as) que passaram a se unir em seus países e a buscar a constituição de Entidades que tivessem essa marca e a explicitação, sem medo e sem vergonha, de dizer que a Psicologia também é uma Profissão histórica e socialmente constituída.

Assim, ao longo destas quase cinco décadas, Sílvia Lane defendeu a construção de uma Psicologia Social que fosse Brasileira e que fosse Latino-Americana, além de, veementemente, defender que toda Psicologia, por excelência, era também Social! 
Derivam deste percurso e trajetória, laços firmes e profundos de amizade, de companheirismo e de parceria entre vários psicólogas e psicólogos, nos diferentes países, desde México, passando por Porto Rico, Costa Rica, Guatemala, El Salvador, Nicarágua, entrando na América do Sul, através da Venezuela, Colômbia, Peru, Equador, Paraguai, Uruguai, Chile, Argentina e Brasil. Atravessam o Atlântico e têm repercussões na Espanha, França, Portugal, e entre outros lugares que, por ventura, ainda não saibamos...

Trata-se de laços que têm a marca daquilo que Sílvia Lane acreditava e que nos alimentou nesta crença: um trabalho conjunto e com uma perspectiva social e coletiva dentro da Psicologia.

Foi através dela que, no Brasil, pudemos ter acesso a várias obras de nossos amigos e colegas latino-americanos, localizando-se as contribuições de Ignácio Martín-Baró, dos (as) psicólogos (as) de Porto Rico, de Venezuela, Chile, Costa Rica, entre tantos outros, que sempre eram trazidos em suas inúmeras falas e participações; mesmo que tais discussões pudessem ser mal vistas pelas forças da opressão.

\section{O Enfrentamento das Forças Repressivas e o Caráter Político da Psicologia}

As forças de repressão nunca tiveram poder de intimidar Sílvia Lane. Ao contrário. Ela as enfrentava como uma marca de sua coerência com a vida e a justiça que sempre defendia. Quando ocupava o cargo de Pró-Reitora Acadêmica da PUC-SP, em fins dos anos 70, a polícia repressora do Estado de São Paulo invadiu violentamente o campus desta Universidade, ferindo severamente vários alunos. Neste momento, pronta e aguerridamente, Sílvia Lane pôs-se ao lado dos estudantes e professores e assumiu, publicamente, posições enérgicas ao exigir a saída da polícia repressora, recebendo claro apoio da Cúria Metropolitana, na figura de D. Paulo Evaristo Arns e da imprensa paulista.

Esta sua altivez e dignidade, ao lado da firmeza de atitudes no enfrentamento da injustiça, marcavam a pessoa de Sílvia Lane que sempre nos acolhia e que sabíamos que sempre estaria a nos acompanhar, por sua prática de companheirismo e lealdade, coerentemente ligados a isto. Sílvia sempre foi leal à sua crença na vida e na dignidade e isto atravessava às 24 horas de seu dia, seja nas aulas que ministrava, nas reuniões que participava, nas conferências e trabalhos que desenvolvia nos inúmeros lugares do Brasil e do exterior, sempre, cotidianamente, regados por uma disposição, alegria e companheirismo de trabalhar e colaborar em igual medida. A cada viagem e participação em que defendia esta Psicologia comprometida, Sílvia Lane se renovava e nos renovava em nossa tarefa de, também, ajudarmos nesta construção. Este é um dos legados de Sílvia e esta é uma de nossas responsabilidades, a todos aqueles que tiveram Sílvia em suas vidas, ela entrou em nossas vidas!

Campos como a Psicologia Social, a Psicologia (Social) Comunitária e a Psicologia Política - no Brasil e na América Latina - passam a ter um significado único e singular quando surgem e se fortalecem tendo o matiz e a influência de Sílvia Lane. Ela sempre foi uma das maiores defensoras da Psicologia em nosso país e continente. Teve sempre a capacidade de aglutinar, mesmo quando era implacavelmente crítica, mas sempre respeitadora e, por isto mesma, soube trazer os adversários para uma luta pela profissão e pela produção ligada à nossa realidade.

Já nos anos 60 e 70, Sílvia Lane falava do caráter político da Psicologia e, em certa medida, ela foi a madrinha da Psicologia Política que vai se fortalecendo, também, no Brasil, já em meados dos anos 80 dentro desta vertente de politização da consciência, como se referia.

Um marco na história da Psicologia Social no Brasil é a fundação da Associação Brasileira de Psicologia Social (ABRAPSO), em 1980, sob a liderança de Sílvia Lane que a presidiu por vários anos e dela sempre participou ativamente. A ABRAPSO representa, na sua trajetória de afirmar o compromisso sócio-político da Psicologia, a democratização do saber acadêmico, o diálogo interdisciplinar e a produção coletiva, a chama viva do espírito da sua fundadora.

Os Trabalhos da Psicologia Comunitária (posteriormente denominados de Psicologia Social Comunitária) surgem fortemente nos projetos e intervenções em que Sílvia Lane, em meados dos anos 60, dá início a uma forma diferente de fazer Psicologia - ao lado e com o povo, comprometendo-se com sua realidade de vida, dentro de uma perspectiva dialética e histórica. Iniciase, então, a explicitação desta clara aproximação entre esta maneira de fazer Psicologia e as concepções filosóficas da proposta de Paulo Freire.

Assim, o conteúdo e a dinâmica da realidade social, assim como a vida da nossa América Latina, aparecem claramente nesta Psicologia defendida e construída por Sílvia Lane, ao longo de sua vida.

E isto, em um tempo em que poucos - pouquíssimos - eram os que falavam, acreditavam e defendiam estas concepções, ou seja, que defendiam o compromisso político-social dos profissionais de Psicologia.

Em outras palavras, defendia a profissão historicamente construída como Ciência e como Práxis.

Mesmo sendo um tempo em que tais posições eram pouco seguras dentro do clima político de exceção e repressão em que vivíamos, Sílvia Lane nunca recuou. E mais, sempre acreditou que isto era nossa tarefa, já que 
esta maneira de fazer Psicologia seria a única capaz de desnudar a vida de injustiças e desigualdades em que nossa população vivia, buscando alternativas ou formas de intervenção em comunidade.

Assim foi... assim fez... assim Sílvia Lane dedicou sua vida á Psicologia Brasileira e Latino-Americana.

\section{As Pessoas Não Morrem, Ficam Encantadas}

Na noite de sábado, 29 de abril de abril de 2006, quando a notícia do falecimento de Sílvia rapidamente se alastra e um forte sentimento de pesar, tristeza e orfandade nos invade, os inúmeros colegas, amigos, parceiros de trabalho e vida de Sílvia Lane começaram a se manifestar, vindos de todas as partes do Brasil e da América Latina e, logo em seguida, da Europa e EUA.

Sílvia Lane nos diria - como lhe era típico e isto emergiria como uma marca sua, de alegria e delicadeza de alma - que este "fato" tratar-se-ia de uma triste, mas necessária contradição. Ou seja, que poderíamos, a partir de agora, estar sem ela e/ou órfãos, mas que este sentimento nos uniria mais ainda, e que poderia nos fazer mais fortes. Diria ela enfaticamente: "isso deveria nos fazer mais fortes!"

Muitas vezes ouvimos Sílvia Lane dizer isto, em várias situações, e diante dos mais adversos e quase invencíveis desafios em nosso campo de atuação e em nossas vidas.

Assim foi quando soube do assassinato de seu grande amigo e irmão de alma Ignácio Martín-Baró em El Salvador, na madrugada de 16 de novembro de 1989. Sílvia, no dia seguinte, telefona ${ }^{2}$ para Vitória, para falar disto, com a voz triste e embargada de dor, mas ao mesmo tempo indignada e afirmando que fizéssemos, como entidade ABRAPSO, um manifesto de "repúdio a tal ultrajante fato e que não podíamos deixar a história e a memória de Ignácio se apagarem". Rapidamente, com o apoio de Sílvia, iniciamos um movimento no Brasil e na América Latina contatando os inúmeros amigos e psicólogos na manifestação deste repúdio, embora o governo de El Salvador tivesse feito todos os caminhos de neutralização das várias mobilizações. Estas foram as palavras de Sílvia naquela ocasião! Estas sempre foram as posições de Sílvia em sua vida! Esta é Sílvia em nossas vidas!

Quem passou por Sílvia Lane, ou melhor, quem teve o privilégio de tê-la em sua vida, sabe da força desta mulher, humana e sensível, que buscou manter a coerência entre o que acreditava e defendia na vida, e o que buscava na formação de nossa profissão.

Graças a isto, também, Sílvia Lane encontrou, mesmo nos adversários teóricos e epistemológicos, um grande respeito e uma parceria diante de questões que podiam afetar a todos nós. Por isto mesmo, acreditamos que a memória e a sua trajetória de vida e os princípios pelos quais lutou, poderiam e deveriam receber, por parte de todos nós, uma singular, inequívoca e forte homenagem. E, assim, se podemos, todos nós, fazer uma Homenagem, justa e que honre a trajetória de vida da Professora Doutora Sílvia Tatiana Maurer Lane e os princípios pelos quais lutou e defendeu, é que possamos, cada um de nós, em seus lugares de atuação e trabalho, ter a mesma postura de comprometimento político-social com a realidade de nossa gente e com os problemas que assolam esse cotidiano. Isto é o que Sílvia nos diria.

$\mathrm{O}$ que podemos hoje dizer, ao buscar recompor alguns dos momentos privilegiados que tivemos com e ao lado de Sílvia?

Ao menos, algumas certezas.

Uma, de que Sílvia Lane passou e entrou em nossas vidas e isto foi "algo" privilegiado que nos fez pessoas mais sensíveis ao nosso lugar dentro da Psicologia e da sociedade. Aqueles que tiveram esta oportunidade acreditam que hão de concordar conosco.

Outra certeza, de que a nossa Psicologia Brasileira, e em especial a Psicologia Social e Comunitária, e parte da Psicologia Política, não seriam o que se apresentam hoje e nem teriam desbravados os caminhos pelos quais temos passado, se não houvéssemos tido a presença e a marca de uma pessoa e trabalhadora social e científica como Sílvia Lane.

Embora todos saibamos disto, talvez Sílvia Lane comece, agora, a receber o reconhecimento por seu trabalho incansável, ao longo destas quase cinco décadas, por esta Psicologia comprometida com a realidade social. Para nós, ao lado de outros importantes nomes como Paulo Freire, Florestan Fernandes e Ignácio Martín-Baró - que, aliás, eram seus amigos e colegas de luta e trabalho na PUC-SP, ou na América Latina - Sílvia Lane é outro nome cuja importância e significado estas simples páginas pretenderam dizer um pouco da grandeza de alma desta mulher e da constante paciência e crença que sempre teve em seus caminhos de luta. Assim, também foi durante os últimos tempos quando já estava bem enferma e, mesmo assim, dispôs-se e atravessou de São Paulo a Panamá, parando para troca de vôo até San José (Costa Rica), e depois por estrada fez uma viagem difícil, pouco confortável e demorada (mais de 5 horas) até Libéria, para poder participar de seu último Congresso Internacional (VIII Congresso Internacional de Psicologia Social de la Liberación), em novembro de 2005. Lá, mesmo enfraquecida e com sua voz tênue e fininha, mas sempre firme, apresentava, com a mesma crença, paixão e grandiosidade, os princípios norteadores desta Psicologia latino-americana. A sala cheia com alunos e pesqui- 
sadores, sentados ao chão e em pé encostados nas paredes, víamos nossa Sílvia Lane a plantar mais algumas sementes e nos dizer, de novo, que a tarefa, agora, era nossa! Sua voz fina e enfraquecida, ao lado de um impecável silêncio em que todos embevecidos a ouvíamos, fazia deste cenário uma imagem especial, ao mesmo tempo delicadamente humana e docemente forte, como sempre foi sua vida e suas atitudes para com as pessoas que a cercavam! Esta era a nossa Sílvia, de sempre!

Escrever sobre alguém como Sílvia Lane, não é fácil e nem simples e é de extrema emoção. Mas também é nosso dever e nosso compromisso, especialmente porque tivemos o prazer de com ela conviver e ter tido Sílvia Lane em nossas vidas, nas mais diferentes situações. Quem pôde viver isto não saiu ileso deste privilégio!

Curitiba e Recife, maio de 2007.

\title{
Notas
}

1. Depoimento de Ana M. B. Block, na contracapa do livro "Silvia Lane", de Bader Sawaia (2002).

2. Nesta ocasião, Helerina A. Novo era vice-presidente da Regional ABRAPSO - Espírito Santo e Maria de Fátima Quintal de Freitas, em Vitória também, era Presidente Nacional da ABRAPSO.

Helerina Aparecida Novo é doutora em Psicologia Social. Professora aposentada da Universidade Federal do Espírito Santo (UFES). Professora do curso de Psicologia da Faculdade Boa Viagem-IMIP, Recife, PE. Endereço para correspondência: Faculdades Boa Viagem,

Rua Jean Favre, 422, Recife, PE

helenovo@terra.com.br

Maria de Fátima Quintal de Freitas é psicóloga; mestre e doutora em Psicologia Social. Professora Adjunta da Universidade Federal do Paraná (UFPR). Endereço para correspondência: UFPR, Setor de Educação, Rua General

Carneiro, 460, Curitiba, PR

fquintal@terra.com.br

\author{
A Militante \\ Suely Rolnik, Pedro Guareschi, Alberto Abib Andery, \\ Apoliana Groff, Josiele Lahorgue, Helerina Aparecida Novo \\ e Maria de Fátma Quintal de Freitas \\ Recebido: 24/05/2007 \\ Aceite final: 14/09/2007
}

